\title{
Alfacalcidol prevents aromatase inhibitor (Letrozole)-induced bone mineral loss in young growing female rats
}

\author{
Idris Mohamed and James K Yeh \\ Metabolism Laboratory, Winthrop-University Hospital, Mineola, New York 11501, USA \\ (Correspondence should be addressed to I Mohamed; Email: mhidris@yahoo.com)
}

\begin{abstract}
Long-term aromatase inhibitor use causes bone loss and increases fracture risk secondary to induced estrogen deficiency. We postulated that alfacalcidol (A; vitamin $\mathrm{D}_{3}$ analog) could help prevent the Letrozole (L)-induced mineral bone loss. Fifty intact 1-month-old female rats were randomly divided into basal group; age-matched control group (AMC); L group: oral administration of $2 \mathrm{mg} / \mathrm{kg}$ per day; A group: oral administration of $0 \cdot 1 \mu \mathrm{g} / \mathrm{kg}$ per day; and group L + A for a period of 8 weeks. Eight-week administration of $L$ resulted in a significant increase in body weight, bone length, bone area, bone formation, and bone resorption activities when compared with the AMC group. However, the bone mass and bone mineral density (BMD) were significantly lower than the AMC group. Serum levels of testosterone, LH, FSH, and IGF-1 were significantly
\end{abstract}

higher and serum estrone and estradiol were lower along with a decrease in ovary + uterus horn weight, when compared with the AMC groups. None of those parameters were affected by A treatment, except suppression of bone resorption activities and increased trabecular bone mass and femoral BMD, when compared with the AMC group. Results of $\mathrm{L}+\mathrm{A}$ combined intervention showed that bone length, bone area, and bone formation activities were higher than the AMC group, and the bone resorption activities were lower and BMD was significantly higher than that of the L group. This study demonstrates that the combined intervention of $\mathrm{L}$ and $\mathrm{A}$ not only enhances bone growth, but also increases bone density, and the effects of $\mathrm{L}$ and $\mathrm{A}$ are independent and additive.

Journal of Endocrinology (2009) 202, 317-325

\section{Introduction}

Short stature associated with constitutional growth delay of puberty (CGDP), idiopathic short stature (ISS), and isosexual precocious puberty represent a pediatric endocrine challenge. Aromatase inhibitor (Letrozole, L) is an emerging therapeutic tool that can be of great hope for those children (Dunkel \& Wickman 2001, Shulman et al. 2008). When children start their early puberty, estrogen has a major role in shaping and dictating future bone health through initiation of modeling that includes all stages of mineral acquisition, linear growth of long bone, and growth plate closure. During adulthood, remodeling is established to help keep bone mass and strength (Frost 2004), and estrogen plays a major role in the remodeling process also (Compston 2001, Vanderschueren et al. 2004).

Estrogen, mainly $17 \beta$-estradiol $\left(\mathrm{E}_{2}\right)$ via estrogen receptor $\alpha$ $(\mathrm{ER} \alpha)$, is an essential regulator of bone maturation, growth plate fusion, and cessation of longitudinal growth (Nilsson et al. 2001).

During puberty, the maximal acquisition of bone mineral is achieved (Finkelstein et al. 1992, Bonjour 1998) via the effect of estrogen through the nuclear receptor $\mathrm{ER} \alpha$, and its modulator, ER $\beta$ (Bord et al. 2001, Nilsson et al. 2001,
Heldring et al. 2007). During this critical period of growth, children suffering from CGDP have reduced bone mineral acquisition with subsequent osteopenia in adult life (Finkelstein et al. 1992, Bonjour 1998); a clinical situation that will be further complicated by the use of L. During adult life, estrogen plays an important role in bone remodeling to maintain density, mineral content, and strength in both human males and females. Clinically, when there is estrogen deficiency, as in postmenopausal women, it is associated with bone mineral loss and osteoporosis (Albright et al. 1941, Riggs et al. 2002). Genetic estrogen deficiency states due to aromatase defects, and genetic ER resistance associated with severe osteopenia, and continued linear growth of the long bone with failure of growth plate closure (Carani et al. 1997), illustrate the major role of estrogen in bone maturation, and achieving final adult height.

$\mathrm{L}$ is a non-steroidal inhibitor of the aromatase enzyme system that is related to cytochrome P495. L, a potent competitive inhibitor of CYP2A6, moderately inhibits CYP2C19, and has a low affinity for CYP3A4. L causes depletion of estrogen via suppression of testosterone conversion to $\mathrm{E}_{2}$ (Buzdar \& Howell 2001, Buzdar 2003). This effect is utilized to increase the predicted adult height, in children with ISS and CGDP (MacGillivray et al. 1998, 
Dunkel \& Wickman 2001, Shulman et al. 2008). CGDP is reported in literature to be associated with reduced bone mineral acquisition, and reduced bone mass in adult life (Finkelstein et al. 1992, Bonjour 1998). The population of children with CGDP may utilize the $\mathrm{L}$ to improve the predicted adult height, and the induction of an estrogen deficienct state after the treatment may further compromise the bone mineral acquisition (Carani et al. 1997, MacGillivray et al. 1998, Dunkel \& Wickman 2001).

The emerging role of aromatase inhibitors in pediatrics and in breast cancer therapy stimulates a need to find a therapeutic intervention that can prevent or even reverse the bone mineral loss associated with the aromatase inhibitor $(\mathrm{L})$.

$1 \alpha$-Hydroxyvitamin $\mathrm{D}_{3}$ (alfacalcidol, $\mathrm{A}$ ), a pro-drug analog of calcitriol, has been used to prevent age-related bone loss in aged male rats ( $\mathrm{Li}$ et al. 2004) and to treat postmenopausal women with osteoporosis (Nuti et al. 2006). A has been effectively used to prevent glucocorticoid-induced bone mineral loss in laboratory animals (Turnquist et al. 1992, Iwamoto et al. 2007). However, the efficacy of $\mathrm{A}$ in preventing bone loss induced by $\mathrm{L}$ is not known.

The current study was designed to evaluate the effect of A on preventing bone loss in pre-pubertal female rats treated with $\mathrm{L}$.

Pre-pubertal female rats were used as opposed to male rats, as they have a high level of estrogens $\left(\mathrm{E}_{1}\right.$ and $\left.\mathrm{E}_{2}\right)$ and lower pool of androgen (testosterone). This helps to evaluate the minor changes between both pools of sex steroids secondary to L therapy. Furthermore, female rats achieve their maturity and peak bone mineral deposition much faster than male rats (Jansson et al. 1983, Hefferan et al. 2003, Legato 2003).

\section{Materials and Methods}

\section{Treatment of animals}

Fifty female Sprague-Dawley rats, at 4 weeks of age, were purchased from Hilltop Lab Animals, Inc., (Scottdale, PA, USA). They were maintained on a $12 \mathrm{~h}$ light: $12 \mathrm{~h}$ darkness cycle at $22{ }^{\circ} \mathrm{C}$ with access to tap water and standard pellet diet (containing 0.93\% calcium, $0 \cdot 65 \%$ phosphorus, and $3 \mathrm{IU} / \mathrm{g}$ vitamin $\mathrm{D}_{3}$ (Robert Laboratory Chow 5001; Ralston Purina, Madison, WI, USA)) ad lib. Ten rats were administered $10 \mathrm{mg} / \mathrm{kg}$ of calcein (Sigma Chemical) at 3 and 7 days after delivery, and then killed on the 8th day as the BASAL group before the experiment. We chose 4 day intervals of calcein labeling when the rats were 5 weeks of age during rapid growth stage, as we intended to avoid the first label resorption before the second calcein injection. One week after reception and adaptation to the environment, the rest of the 40 rats were randomized by stratified weight method into four experimental groups of 10 rats each; agematched control (AMC), L, A, and L + A groups. L (Novartis International Pharmaceutical Ltd) was suspended in oneto-one mixture of distilled water and 1,2-propanediol solution, and was administered orally with a dosage of $2.0 \mathrm{mg} / \mathrm{kg}$ per day in $0.1 \mathrm{ml}$ volume solution. A (Sigma Chemical) was dissolved in ethanol and diluted with salinebuffered solution with ethanol concentration $<1 \%$ and was also orally administered with a dosage of $0 \cdot 1 \mu \mathrm{g} / \mathrm{kg}$ per day in $0 \cdot 1 \mathrm{ml}$ volume. The doses of $\mathrm{L}$ and $\mathrm{A}$ were determined based on the results of previous studies (Shiraishi et al. 2000, Erben et al. 2002, Goss et al. 2004, Gasser et al. 2006). Animals of AMC group received $0.1 \mathrm{ml}$ vehicle saline solution per day. The body weight of the rats was monitored weekly for 8 weeks, the total duration of the experiment. The present study was carried out at the animal facility of the Winthrop University Hospital according to the National Institute of Health guide for Care and Use of Laboratory Animals, and the animal experiment protocols were approved by the Laboratory Animal Care Committee of WinthropUniversity Hospital.

\section{Preparation of specimens}

Our previous experience suggests that 4 day intervals of calcein injection would be too short to distinguish the double labeling clearly when the animal's age is over 3 months or more, as their bone formation and bone turnover rates decrease compared with that of the 1-month-old animal. Therefore, all the rats, except the BASAL group, were labeled with $10 \mathrm{mg} / \mathrm{kg}$ of calcein (Sigma Chemical) injected i.m. 10 days and 3 days before they were killed. The animals were anesthetized with $80 \mathrm{mg} / \mathrm{kg}$ of ketamine injected i.p., together with $12 \mathrm{mg} / \mathrm{kg}$ of xylazine, and were killed by exsanguinations. The serum, right femurs, and the right tibiae were collected.

\section{Serum biochemical analysis}

Serum calcium levels were measured by an automated instrument (Dada Behring Model RXL., Bakersfield, CA, USA). Serum $E_{1}, E_{2}$, testosterone, $\mathrm{LH}$, and $\mathrm{FSH}$ were measured using commercial kits (ALPCO Diagnostics, Salem, NH, USA). Serum levels of insulin-like growth factor-1 (IGF-1) were measured using rat-specific RIA kit (DSL, Inc. Webster, TX, USA). Serum levels of procollagen 1 $\mathrm{N}$-terminal propeptide (P1NP) as a bone formation marker (Melkko et al. 1996, Jensen et al. 1998, Shankar \& Hosking 2006, Rissanen et al. 2008) were measured using rat-specific ELISA kit (IDS Inc. Fountain Hills, AZ, USA).

The femurs were used for the measurement of bone length, bone area, bone mineral content (BMC), and bone mineral density (BMD), as described below. The tibiae were used for static and dynamic bone histomorphometric analyses. The bones were fixed overnight in $40 \%$ cold ethanol, and then cut into three parts using an Isomet saw (Buehler, Lake Bluff, IL, USA). The proximal tibial metaphysis and tibial diaphysis with the fibular junction were stained with Villanueva Osteochrome Bone Stain (Polyscience, Warrington, PA, USA) for 5 days. The specimens were then dehydrated 
sequentially in ascending concentrations of ethanol (70, 95, and $100 \%$ ) and xylene, and then embedded in methyl methacrylate (EM Science, Gibbstown, NJ, USA) at $42{ }^{\circ} \mathrm{C}$. Cross-sections of the tibial diaphysis, just proximal to the tibia-fibular junction, were sectioned at $8 \mu \mathrm{m}$ thickness, and frontal sections of the proximal tibial metaphysis were sectioned at $5 \mu \mathrm{m}$ thickness using a microtome (Leica RM2155; Leica Inc., Nussloch, Germany) then transferred onto chromium-gelatin-coated slides, dried overnight under pressure at $62{ }^{\circ} \mathrm{C}$, and cover slipped with Eukitt mounting medium (Calibrated Instruments, Hawthorne, NY, USA) for static and dynamic histomorphometric analyses.

\section{Bone histomorphometric analysis of the tibia}

A digitizing morphometric system was used to measure bone histomorphometric parameters. The system consisted of an epifluorescence microscope (Nikon E-400, OsteoMetrics, Atlanta, GA, USA), an Osteomeasurement High Resolution Color Subsystem (OsteoMetrics) coupled to an IBM computer, and a morphometry program (OsteoMetrics). The measured parameters for cancellous bone included total tissue volume (TV), trabecular bone volume (BV), bone surface (BS), erosion surface (ErS), single- and double-labeled surfaces (sLS and dLS respectively), and interlabel width. These data were used to calculate percent trabecular BV/TV, trabecular number $(\mathrm{Tb} \mathrm{N})$, trabecular thickness $(\mathrm{Tb} \mathrm{Th})$, trabecular separation ( $\mathrm{Tb} \mathrm{Sp}$ ), mineralizing surface (MS)/BS $((\mathrm{sLS} / 2+\mathrm{dLS}) / \mathrm{BS})$, mineral apposition rate (MAR), bone formation rate (BFR)/BS, and ErS/BS, in accordance with the standard nomenclature proposed by Parfitt et al. (1987). In the present study, the region of trabecular bone measured in the BASAL group rats was $1.5-4.5 \mathrm{~mm}$ distal to the lower margin of the growth plate in the proximal tibial metaphysis, while in the remaining four experimental groups was 1-4 mm distal to the lower margin of the growth plate. Since the animals in the BASAL group were 4 weeks old and were growing rapidly, it was necessary to skip $1.5 \mathrm{~mm}$ beneath the growth plate in order to avoid primary spongiosa. The area measured from 1.5 to $4.5 \mathrm{~mm}$ consists of secondary spongiosa and can be comparable with that of the 3-months-old experimental groups. In addition to the measurement of the above parameters, interlabel width beneath the growth plate was used to calculate longitudinal growth rate (LGR/day). The measured parameters for cortical bone were total tissue area, medullary area, and periosteal and endocortical BS, sLS, dLS, ErS, and interlabel width. These data were used to calculate cortical area, periosteal and endocortical MS/BS ((sLS/2+dLS)/BS), MAR, BFR/BS, and endocortical ErS/BS.

\section{Femoral bone area, $B M C$, and $B M D$}

Bone area, BMC, and BMD of the whole right femur were determined by dual energy X-ray absorptiometry (DXA) using a Hologic QDR-4500 Plus (Hologic Inc.,
Bedford, MA, USA). The instrument was adapted for an ultra-resolution mode, with a line spacing of $0.0254 \mathrm{~cm}$, resolution of $0.0127 \mathrm{~cm}$, and collimation of $0.9 \mathrm{~cm}$ diameter. The bone was placed in a petri dish, and to simulate soft-tissue density, tap water was poured around the bones to a depth of $1 \mathrm{~cm}$. BMC and bone area were measured, and BMD of this area was calculated by dividing BMC by bone area. The coefficient of variation of these measurements at our laboratory was $<1 \cdot 0 \%$ (Iwamoto et al. 2007, Shen et al. 2008).

\section{Statistical analysis}

All the data was expressed as means and S.D. Multiple comparisons of data among the groups were performed by ANOVA with the Tukey-Kramer test. Two-way ANOVA was used to evaluate the respective effect of $L$ and $A$ and their interaction. All statistical analyses were performed using Prism-5.0 program on a Hewlett Packard computer. A minimal significance level of $P<0.05$ was used for all the comparisons.

\section{Results}

Table 1 shows that there was no significant difference in the initial body weight among the experimental groups. The final body weight of the BASAL group was not different from the initial experimental groups either. In comparison with BASAL and AMC groups, animals of the BASAL group were in a rapid growth stage with relative high in LGR/day. After the 8-week experiment, LGR was decreasing with age; the bone length, size, and the density of femur were increasing. The final body weight, tibial LGR/day, femoral length, and bone area of the $\mathrm{L}$ group were significantly higher, and the weight of ovary + uterine horn and the femoral BMD was significantly lower than that of the AMC group. The final body weight, ovary + uterine horn weight, tibial LGR/day, and femoral length of the A group were not significantly different from that of the AMC group, but the femoral bone area, $\mathrm{BMC}$, and the BMD were significantly higher than that of the AMC group. The combined intervention of $\mathrm{L}+\mathrm{A}$ resulted in, not only a further increase in the body weight and femoral bone area, but also in an increase in the femoral BMC and BMD when compared with the L group. Results of twoway ANOVA showed that the effects of $\mathrm{L}$ on body weight, ovary + uterine horn weight, tibial LGR/day, femoral length, bone area, BMC, and BMD were significant, and the effects of A on body weight gain, femoral bone area, BMC, and BMD were significant. None of these parameters had any significant interaction between the $\mathrm{L}$ and $\mathrm{A}$ treatments. Therefore, these treatment effects are independent with a positive additive effect.

Table 2 shows that $\mathrm{L}$ had no significant effect on serum levels of calcium, but it significantly decreased the levels of $\mathrm{E}_{1}$ and $\mathrm{E}_{2}$, and increased the testosterone, LH, FSH, IGF-1, and P1NP when compared with the AMC group. In comparison 


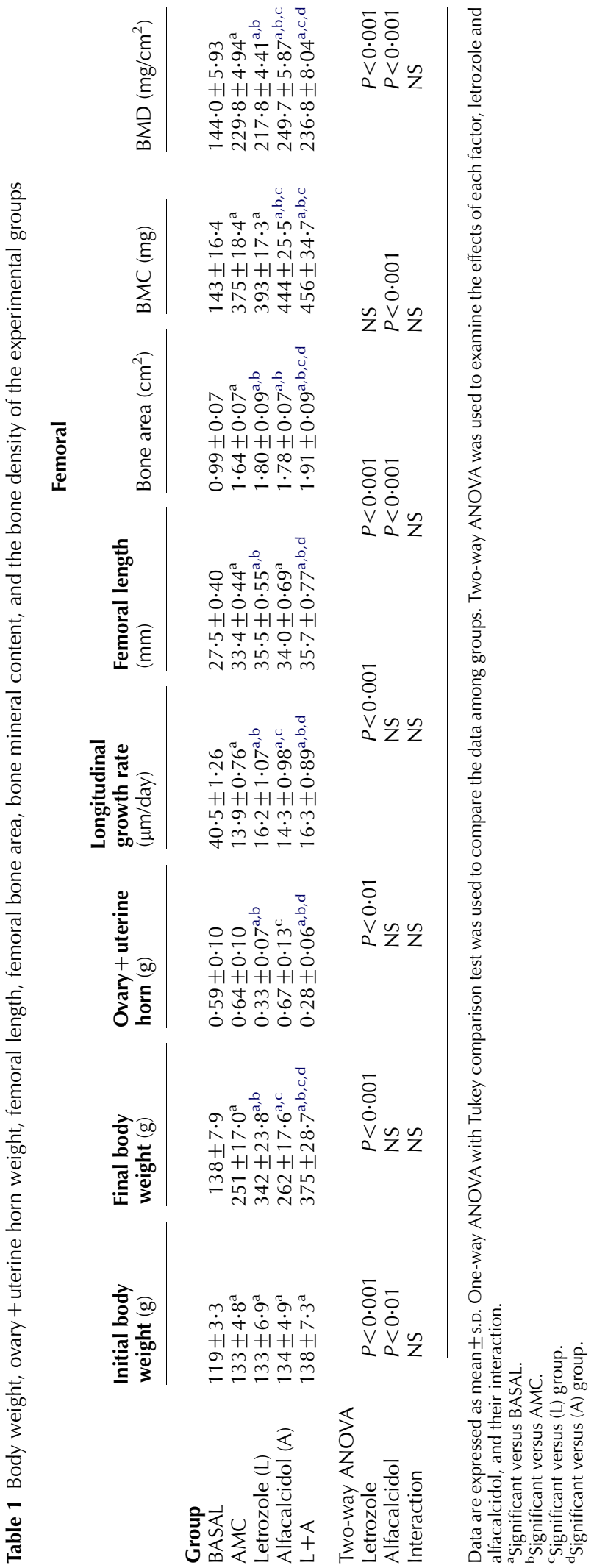

with the AMC group, A administration resulted in a significant increase in serum levels of calcium, but had no significant effect on the serum levels of $\mathrm{E}_{1}, \mathrm{E}_{2}$, testosterone, LH, FSH, IGF-I, or P1NP. The experimental animals' daily intake of dietary vitamin $\mathrm{D}_{3}$ was $\sim 1 \cdot 1 \mu \mathrm{g}$, calculated based on daily intake of chow diet $15 \mathrm{~g}(15 \mathrm{~g} \times 3 \mathrm{IU} / \mathrm{g}=45 \mathrm{IU}$ or $1 \cdot 1 \mu \mathrm{g}$ of vitamin $\left.\mathrm{D}_{3}\right)$. Yet, a daily supplementation of $\mathrm{A}$, $0 \cdot 026-0 \cdot 038 \mu \mathrm{g}(0 \cdot 1 \mu \mathrm{g} / \mathrm{kg}$ per day $)$ in the $\mathrm{A}$ and $\mathrm{A}+\mathrm{L}$ groups, resulted in a significant increase in serum calcium when compared with the AMC group. It showed that A is a highly potent vitamin $\mathrm{D}$ analog. This dose of A did not result in hypercalcemia in the current study. As an effect of $A$, the $\mathrm{L}+\mathrm{A}$ combined intervention also resulted in an increase in the serum calcium, and as a result of $\mathrm{L}$, there was a decrease in the $\mathrm{E}_{1}$ and $\mathrm{E}_{2}$ levels and increase in the testosterone, LH, FSH, IGF-1, and P1NP. Significant interactions of A and L on serum $E_{1}, E_{2}$, and $L H$ respectively indicate that the combined intervention of $\mathrm{A}$ and $\mathrm{L}$ results in a further suppression of these serum levels. The significant interaction on serum $\mathrm{P} 1 \mathrm{NP}$ indicates that the augmentation of P1NP by the $\mathrm{L}$ was suppressed by the A in combined intervention.

The static histomorphometry of trabecular bone in the proximal tibial metaphysis and cortical bone of the crosssection at proximal to the tibia-fibular junction was shown in Table 3. In comparison with BASAL and AMC groups, the trabecular BV (\%) and thickness and the cortical total area and cortical bone in percentage were increased during the 8 week growth. L administration resulted in a significant decrease in the trabecular BV/TV and the $\mathrm{Tb} \mathrm{N}$ and an increase in the $\mathrm{Tb} \mathrm{Sp}$ when compared with the AMC group. Conversely, A administration resulted in a significant increase in the BV/TV, $\mathrm{Tb} \mathrm{Th}$, and $\mathrm{Tb} \mathrm{N}$ and a decrease in the $\mathrm{Tb} \mathrm{Sp}$ when compared with the AMC group. The results of combined intervention showed that trabecular bone mass, $\mathrm{BV} / \mathrm{TV}$, and the microarchitecture, $\mathrm{Tb} \mathrm{Th}$, and $\mathrm{Tb} \mathrm{N}$ were higher and $\mathrm{Tb} \mathrm{Sp}$ was lower than the $\mathrm{L}$ group. Two-way ANOVA showed that the effects of $\mathrm{L}$ and $\mathrm{A}$ on those parameters were independent.

The results of cortical bone did not show any significant difference among the experimental groups on total area, cortical area, or the cortical area in percentage (Table 3). However, the result of two-way ANOVA showed a significant effect of the increase by $\mathrm{L}$ on the total area, cortical area, and medullar area, and also an increased effect of A on the cortical area gain without a significant effect on the cross-sectional total area. The two significant interactions of $\mathrm{L}$ and $\mathrm{A}$ indicate a synergistic effect of the increase on bone gain in cortical area and a suppression effect of the increase on medullar area induced by $\mathrm{L}$ in the combined intervention.

While the experimental animals were rapidly growing during this 8-week period, the comparison of AMC with the BASAL groups shows that trabecular formation parameters, MS/BS, BFR/BS, and the resorption parameter of ErS/BS were decreasing with age (Fig. 1). L administration resulted in a significant increase in both MAR, MS/BS, 


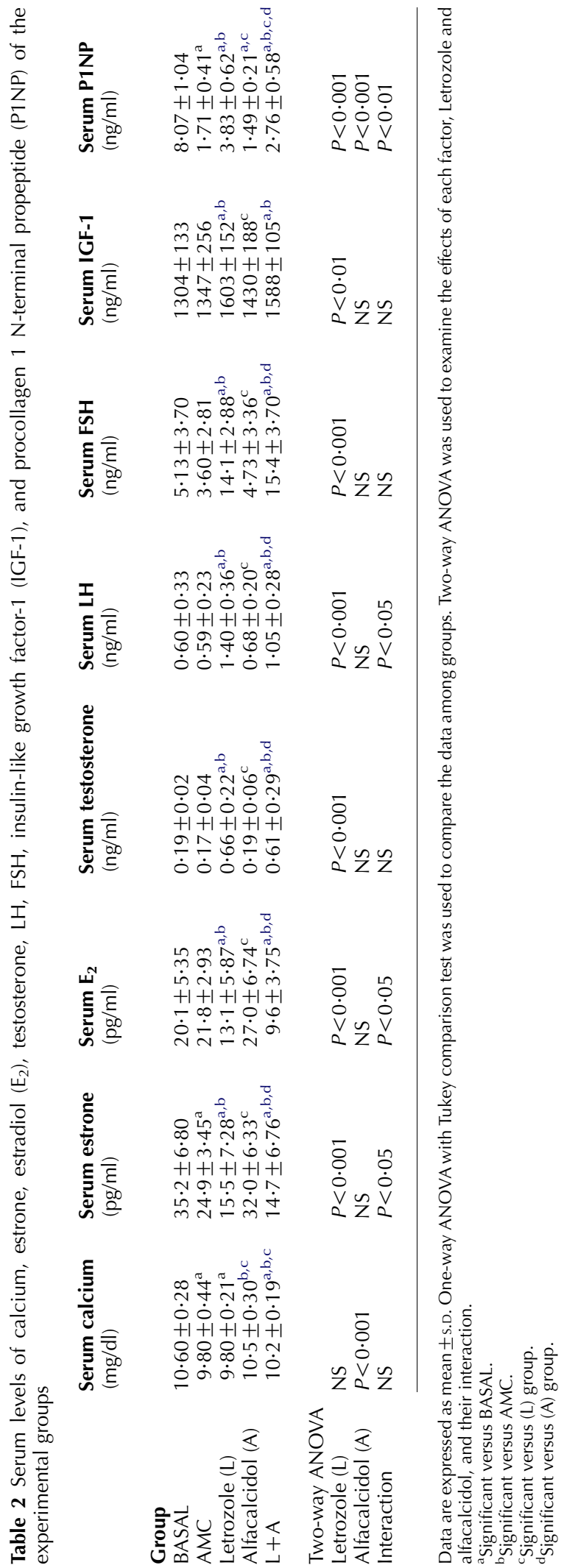

BFR/BS, and the ErS/BS when compared with the AMC group. The trabecular MAR, Ms/BS, and BFR/BS of the A group were not significantly different from the AMC group, but the ErS/BS was significantly lower than the AMC group. The MAR, MS/BS, and BFR/BS of the L+A group were lower than the $\mathrm{L}$ group, but higher than both $\mathrm{AMC}$ and A groups. The ErS/BS of the L+A group was significantly lower than the $\mathrm{L}$ group, and not different from the AMC group.

In comparison with the AMC and BASAL groups, Figures 2 and 3 show that periosteal and endocortical bone formation parameters such as the MS/BS, MAR and BFR/BS, and endocortical ErS/BS (\%) as a resorption parameter were decreasing during this rapid-growth stage. L treatment resulted in a significant increase in the periosteal MAR, $\mathrm{BFR} / \mathrm{BS}$, endocortical MS/BS, MAR, BFR/BS, and the ErS/BS (\%), while A had no significant effect on bone formation parameters of both surfaces, but a significant decrease in the endocortical ErS/BS in percentage in comparison with the AMC group. Bone formation parameters of both surfaces of the $\mathrm{L}+\mathrm{A}$ group were significantly higher than that of the AMC. ErS of the L + A group was higher than the A group and not different from the AMC group.

\section{Discussion}

The emerging role of $\mathrm{L}$ in children with CGDP and ISS prompted our quest to investigate the efficacy of $\mathrm{A}$ in preventing bone mineral loss, while maintaining the therapeutic effect of $\mathrm{L}$ on bone elongation. Bone mineral loss associated with aromatase inhibitor use has been demonstrated in animal experiments and clinical studies (Thurlimann et al. 2005, Gasser et al. 2006). The current finding confirms that even though the experimental animals were in a rapid-growth stage, $\mathrm{L}$ treatment induces further bone elongation, bone area growth, and body weight gain; it also induces significant decrease in percentage of trabecular volume, $\mathrm{Tb} \mathrm{N}$, and BMD. Furthermore, the current study demonstrates that combined intervention of $\mathrm{L}$ and $\mathrm{A}$ does not only enhance bone elongation, bone area enlargement, and body weight gain, but also improves trabecular BV, microarchitecture, and bone density, with concomitant suppression of bone resorption in young rats. We also demonstrate that the effects of $\mathrm{L}$ and $\mathrm{A}$ on bone metabolism, bone density, and serum levels of estrogen and testosterone are independent and additive.

The results of our dynamic histomorphometry and serum bone turnover marker, P1NP, reveal that L treatmentinduced increase in bone turnover rate and significant bone loss is associated with estrogen deficiency, since those phenomena bear a resemblance to the results observed in ovariectomized rat. When we examine the net BMC of L-treated group as measured by DXA, it may not be decreased when compared with the AMC group. Therefore, the 


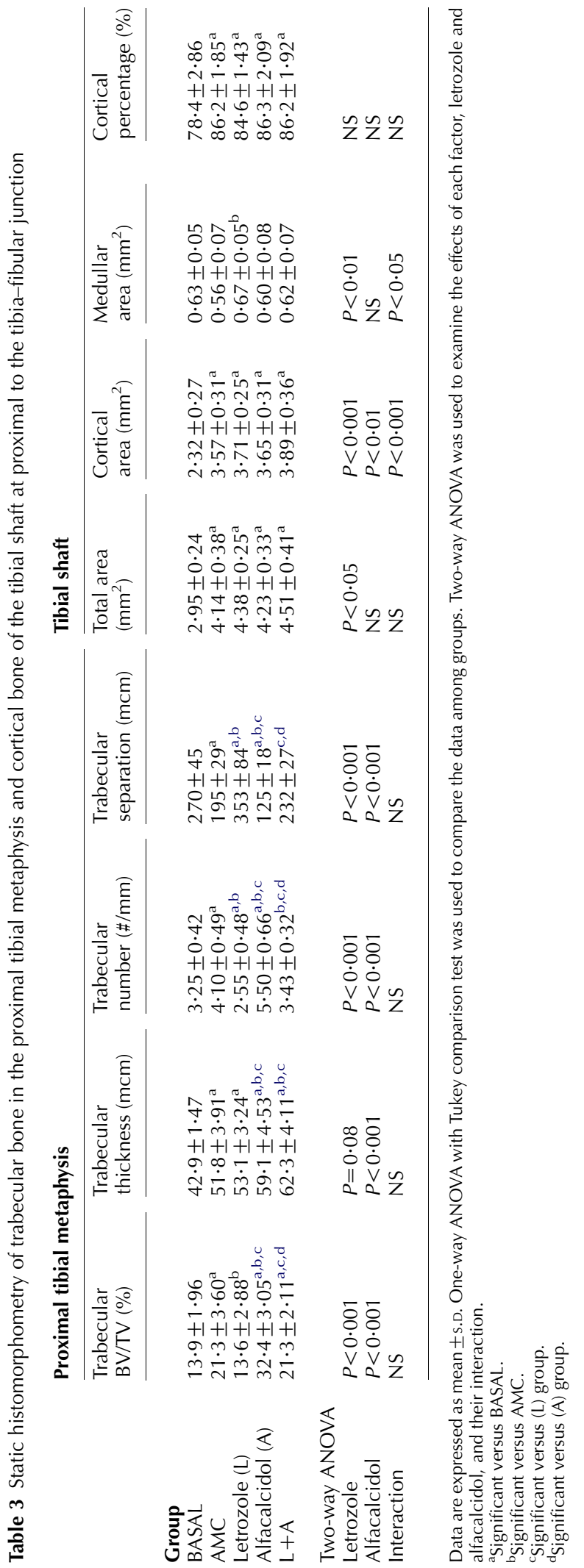

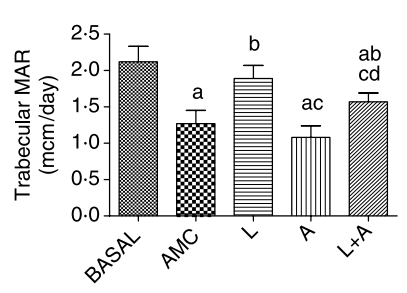
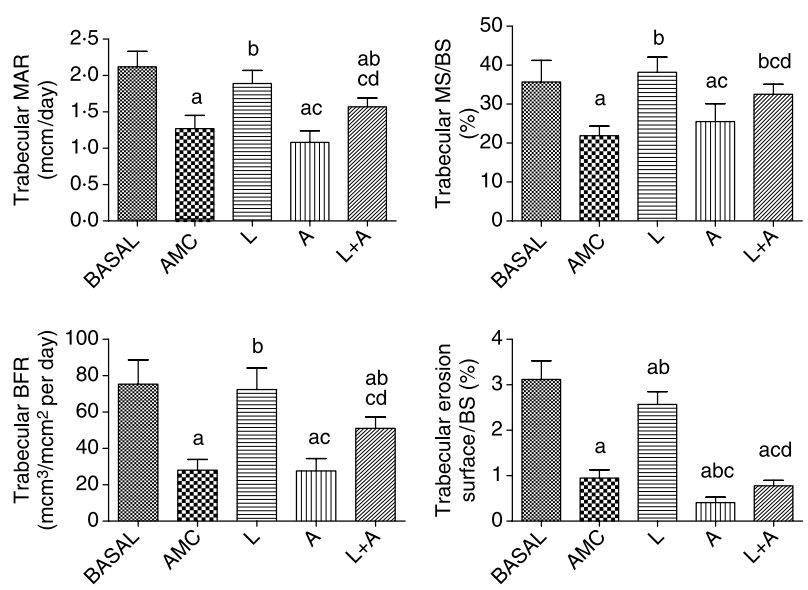

Figure 1 Bone dynamic histomorphometric analysis of trabecular bone of the proximal tibial metaphysis. Data are expressed as mean \pm s.D. ANOVA with Tukey-Kramer test was used to compare the data among the groups $(P<0 \cdot 05)$. a, significant versus BASAL; $b$, significant versus AMC; $c$, significant versus $L$; $d$, significant versus A group. AMC, age-matched control; L, Letrozole; A, alfacalcidol, $\mathrm{L}+\mathrm{A}$, combined treatment of Letrozole and alfacalcidol; MAR, mineral apposition rate; MS/BS, mineralized surface/bone surface; $\mathrm{BFR}$, bone formation rate.

increase in bone area and bone size without a concurrent increase in BMC could also contribute the decrease in the bone density.

Suppression of serum estrogen level is believed to be the primary mechanism through which $\mathrm{L}$ induces BMD loss and enhances bone elongation and bone growth. Our current finding of $\mathrm{L}$ treatment-enhanced serum levels of IGF-I with the increase in serum testosterone levels may provide another explanation of increased long-bone growth beside the cause of estrogen deficiency. In supporting this presumption, serum levels of GH have been reported to be increasing after 10 days of treatment with $\mathrm{L}$ to the peripubertal male mice (Eshet et al. 2004). Although the serum levels of IGF-I was not found to be increasing significantly by a relatively short time of 10 day $\mathrm{L}$ treatment, the IGF-I receptor in the tibial epiphyseal growth plate was reported to be increasing in comparison with the non-treated group. It is known that IGF-I is an important modulator in bone matrix formation, growth plate elongation, and improvement of bone mechanical properties (Van der Eerden et al. 2003). IGF-I has been utilized experimentally to induce new bone formation in an aged mouse model (Meinel et al. 2003), to improve bone mass in women with profound osteoporosis secondary to anorexia nervosa (Grinspoon et al. 1996), and to induce new bone formation in experimental segmental tibial defects (Fowlkes et al. 2006). On the other hand, it has been demonstrated that testosterone directly stimulates the expression of IGF-I receptor and increases chondrocyte proliferation on an in vitro model of mandibular condyle (Maor et al. 1999). Increased IGF-1 receptors are associated with testosterone-stimulated growth plate elongation (Nilsson et al. 1986, Abbaspour et al. 

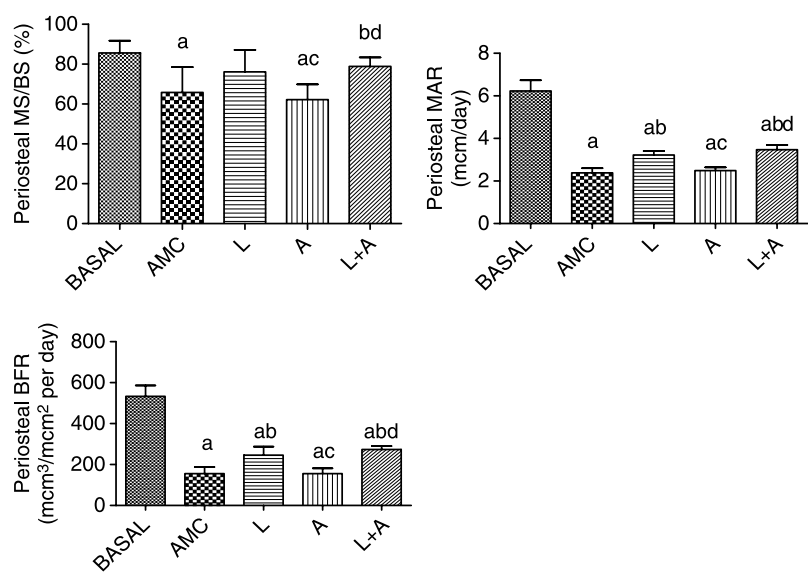

Figure 2 Bone dynamic histomorphometric analysis of periosteal surface of the cortical bone of the tibial shaft. Data are expressed as mean \pm s.D. ANOVA with Tukey-Kramer test was used to compare the data among the groups $(P<0 \cdot 05)$. a, significant versus BASAL; $b$, significant versus AMC; $c$, significant versus $L$; $d$, significant versus $A$ group. $A M C$, age-matched control; $L$, Letrozole; $A$, alfacalcidol; $\mathrm{L}+\mathrm{A}$, combined treatment of Letrozole and alfacalcidol; MAR, mineral apposition rate; MS/BS, mineralized surface/bone surface; BFR, bone formation rate.

2008, Soliman et al. 2008), bone growth (Phillip et al. 2001) and body weight gain via augmentation of $\mathrm{GH}$ at target organs (Zung et al. 1999). Therefore, the increment in serum levels of IGF-I and testosterone, along with the increase in IGF-1 receptors and GH after aromatase inhibitor treatment, indicates that the GH/IGF-1 axes might be involved in mediating the effects of the aromatase inhibitor on the bone elongation and weight gain.

The effect of $\mathrm{A}$ on preventing osteopenia has been demonstrated using numerous animal models, such as ovariectomized rats, orchidectomized rats, aged rats, glucocorticoid-treated rats, and in human subjects (Shiraishi et al. 1999, Nishikawa et al. 2000, Li et al. 2004, Schacht et al. 2005, Iwamoto et al. 2006, 2007, 2008, Ringe et al. 2007, Majima et al. 2008). The anabolic and anti-resorptive properties of $\mathrm{A}$ have been observed and proposed as attributing factors to the increase in bone mass and improvement of bone strength. The effect of $\mathrm{A}$ on bone could be secondary due to an increase in intestinal calcium absorption and changes in parathyroid hormone (PTH), since D-hormone can reduce serum PTH levels (Schacht et al. 2005) and blocking parathyroid gland proliferation and secretion (Szabo et al. 1989, Brown et al. 2006). On the other hand, there is also evidence that A could have directly suppressed osteoclastogenesis in vivo by decreasing the pool of osteoclast precursors in bone marrow (Shibata et al. 2002). Therefore, the beneficial effect of A on bone metabolism is not only due to stimulation of intestinal absorption of calcium, thereby enhancing the positive balance of calcium, but also a significant suppression of endocortical and trabecular bone resorption while maintaining the periosteal, endocortical, and trabecular BFRs, as we observed in the A-treated animals in comparison with the AMC group.

The advantage of combined intervention of $\mathrm{A}$ and $\mathrm{L}$ in promoting growth in young growing stage is that the enhancement of bone elongation, bone area growth, serum levels of IGF-1, LH, FSH, and testosterone by $\mathrm{L}$ is not suppressed by A, but is additive to the anti-resorptive effect of A. Furthermore, the suppression of estrogen by $\mathrm{L}$ is not affected by $\mathrm{A}$ either, and the side effect of $\mathrm{L}$ can be prevented by the combined intervention with $\mathrm{A}$. These findings may imply a difference in functions of these two agents on bone metabolism in young growing rats. A may enhance calcium absorption from the gastrointestinal tract; suppress bone resorption and $\mathrm{PTH}$ secretion, while $\mathrm{L}$ enhances bone modeling and remodeling; increases bone growth and bone turnover. Interestingly, in the combined intervention of $\mathrm{L}+\mathrm{A}$, bone formation activities of the trabecular and periosteal bones remained higher than that of the AMC rat, yet the bone resorption activities of trabecular and endocortical surfaces were suppressed regardless of the serum level of estrogen that was decreased by $\mathrm{L}$ treatment. This indicates that the enhancement of bone gain in the combined treatment is independent from (not affected by) estrogen deficiency.

Such additive effect would be suitable to promote bone growth, bone gain in mass, and bone density and would improve the calcium balance in children with CGDP and ISS.

Third-generation aromatase inhibitors, L, have demonstrated efficacy for the treatment of postmenopausal women with hormone receptor-positive breast cancer as first- and second-line therapy for advanced metastatic disease (Buzdar et al. 2001, Buzdar 2003) via blocking the biosynthesis of
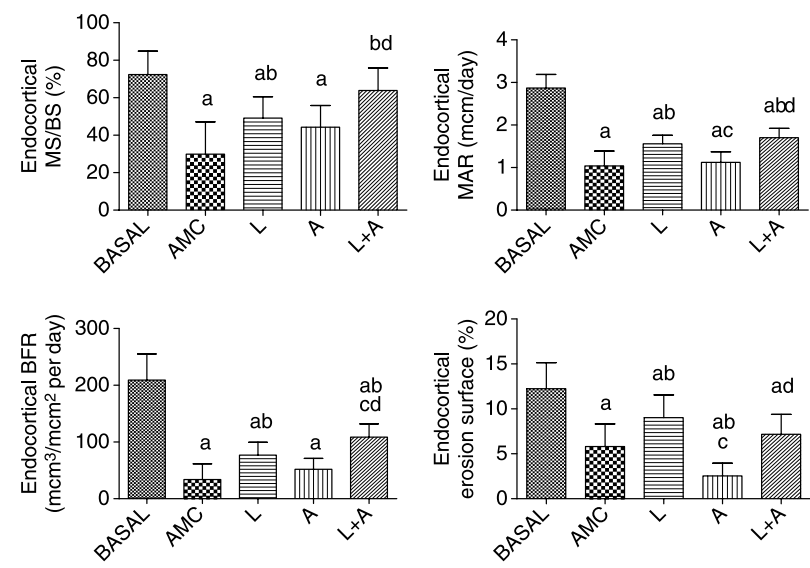

Figure 3 Bone dynamic histomorphometric analysis of endocortical surface of the cortical bone of the tibial shaft. Data are expressed as mean \pm s.D. ANOVA with Tukey-Kramer test was used to compare the data among the groups $(P<0 \cdot 05)$. a, significant versus BASAL; $b$, significant versus $A M C$; $c$, significant versus $L$; $\mathrm{d}$, significant versus A group. AMC, age-matched control; L, Letrozole; A, alfacalcidol; $L+A$, combined treatment of Letrozole and alfacalcidol; MAR, mineral apposition rate; $\mathrm{MS} / \mathrm{BS}$, mineralized surface/bone surface; BFR, bone formation rate. 
estrogen from testosterone. Thus, the theoretical advantage of this combined intervention in application to those women with hormone receptor-positive breast cancer will be preventing bone loss without affecting the suppression of estrogen biosynthesis.

In conclusion, L-treated young, female rats showed significant increase in bone elongation, bone growth with concomitant side effects of increased bone loss, bone separation, and reduced bone density. These side effects were effectively antagonized by the concomitant use of A without affecting the enhancement of long-bone elongation induced by L. This could be of clinical importance among pubertal children treated for CGDP and ISS. On the other hand, the combination therapy could be of great help for breast cancer patients treated with $\mathrm{L}$, to prevent L-associated bone mineral loss in this group of patients, a theoretical advantage that needs further investigation.

\section{Declaration of interest}

The authors declare that there is no conflict of interest that could be perceived as prejudicing the impartiality of the research reported.

\section{Funding}

This work was supported by Idromedical Cor under the service agreement with the Winthrop University Hospital (grant number 350-104).

\section{References}

Abbaspour A, Takata S, Matsui Y, Katoh S, Takahashi M \& Yasui N 2008 Continuous infusion of insulin-like growth factor-I into the epiphysis of the tibia. International Orthopaedics 32 395-402.

Albright F, Smith PH \& Richardson AM 1941 Postmenopausal osteoporosis. Journal of the American Medical Association 116 2465-2474.

Bonjour JP 1998 Delayed puberty and peak bone mass. European Journal of Endocrinology 139 257-259.

Bord S, Horner A, Beavan S \& Compston J 2001 Estrogen Receptors $\alpha$ and $\beta$ are differentially expressed in developing human bone. Journal of Clinical Endocrinology and Metabolism 86 2309-2314.

Brown AJ, Ritter CS, Knutson JC \& Strugnell SA 2006 The vitamin D prodrugs $1 \alpha(\mathrm{OH}) \mathrm{D}_{3}$ and $\mathrm{BCI}-210$ suppress $\mathrm{PTH}$ secretion by bovine parathyroid cells. Nephrology, Dialysis, Transplantation 21 644-650.

Buzdar A 2003 Pharmacology and pharmacokinetics of the newer generation aromatase inhibitors. Clinical Cancer Research 9 468S-472S

Buzdar A \& Howell A 2001 Advances in aromatase inhibition clinical efficacy and tolerability in the treatment of breast cancer. Clinical Cancer Research 7 2620-2635.

Carani C, Qin K, Simoni M, Faustini-Fustini M, Serpente S, Boyd J \& Korach KS 1997 Effect of testosterone and estradiol in a man with aromatase deficiency. New England Journal of Medicine 337 91-95.

Compston JE 2001 Sex steroids and bone. Physiological Reviews 81 419-447.

Dunkel L \& Wickman S 2001 Treatment of delayed male puberty: efficacy of aromatase inhibition. Journal of Pediatric Endocrinology and Metabolism 14 $1541-1546$

Van der Eerden BCJ, Karperien M \& Wit JM 2003 Systemic and local regulation of the growth plate. Endocrine Reviews 24 782-801.
Erben RG, Mosekilde L, Thomsen JS, Weber K, Stahr K, Leyshon A, Smith SY \& Phipps R 2002 Prevention of bone loss in ovariectomized

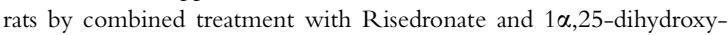
vitamin $\mathrm{D}_{3}$. Journal of Bone and Mineral Research 17 1498-1511.

Eshet R, Maor G, Ari TB, Eliezer MB, Gat-Yablonski G \& Phillip M 2004 The aromatase inhibitor Letrozole increases espiphyseal growth plate height and tibial length in peripubertal male mice. Journal of Endocrinology $182165-172$.

Finkelstein JS, Neer RM, Biller BM, Crawford JD \& Klibanski A 1992 Osteopenia in men with a history of delayed puberty. New England Journal of Medicine 326 600-604.

Fowlkes JL, Thrailkill KM, Liu L, Wahl EC, Bunn RC, Cockrell GE, Perrien DS, Aronson J \& Lumpkin CK Jr 2006 Effects of systemic and local administration of recombinant human IGF-I (rhIGF-I) on de novo bone formation in an aged mouse model. Journal of Bone and Mineral Research 21 1359-1366.

Frost HM 2004 The Utah Paradigm of Skeletal Physiology, ch 3 and 4. Greece: International Society of Musculoskeletal and Neuronal Interactions.

Gasser JA, Green JR, Shen V, Ingold P, Rebmann A, Bhatnagar AS \& Evans DB 2006 A single intravenous administration of zoledronic acid prevents the bone loss and mechanical compromise induced by aromatase inhibition in rats. Bone 39 787-795.

Goss PE, Qi S, Cheung AM, Hu H, Mendes M \& Pritzker KP 2004 Effects of the steroidal aromatase inhibitor exemestane and the nonsteroidal aromatase inhibitor Letrozole on bone and lipid metabolism in ovariectomized rats. Clinical Cancer Research 10 5717-5723.

Grinspoon S, Baum H, Lee K, Anderson E, Herzog D \& Klibanski A 1996 Effects of short-term recombinant human insulin-like growth factor I administration on bone turn over in osteopenic women with anorexia nervosa. Journal of Clinical Endocrinology and Metabolism 81 3864-3870.

Hefferan TE, Evans GL, Lotinun S, Zhang M, Morey-Holton E \& Turner RT 2003 Effect of gender on bone turnover in adult rats during simulated weightlessness. Journal of Applied Physiology 95 1775-1780.

Heldring N, Pike A, Andersson S, Matthews J, Cheng G, Hartman J, Tujague M, Ström A, Treuter E, Warner M et al. 2007 Estrogen receptors: how do they signal and what are their targets. Physiological Reviews 87 905-931.

Iwamoto J, Seki A, Takeda T, Sato Y, Yamada H \& Yeh JK 2006 Comparative therapeutic effects of alendronate and alfacalcidol on cancellous and cortical bone mass and mechanical properties in ovariectomized osteopenic rats. Journal of Nutritional Science and Vitaminology 52 1-8.

Iwamoto J, Seki A, Takeda T, Yamada H, Sato Y \& Yeh JK 2007 Effects of alfacalcidol on cancellous and cortical bone mass in rats treated with glucocorticoid: a bone histomorphometry study. Journal of Nutritional Science and Vitaminology 53 191-197.

Iwamoto J, Takeda T, Matsumoto H, Sato Y \& Yeh JK 2008 Beneficial effects of combined administration of alendronate and alfacalcidol on cancellous bone mass of the tibia in orchidectomized rats: a bone histomorphometry study. Journal of Nutritional Science and Vitaminology 54 11-17.

Jansson JO, Eden S \& Isaksson O 1983 Sites of action of testosterone and estradiol on longitudinal bone growth. American Journal of Physiology. Endocrinology and Metabolism 244 135-140.

Jensen CH, Hansen M, Brandt J, Rasmussen HB, Jensen PB \& Teisner B 1998 Quantification of the N-terminal propeptide of human procollagen type I (P1NP): comparison of ELISA and RIA with respect to different molecular forms. Clinica Chimica Acta 269 31-41.

Legato MJ 2003 Beyond women's health the new discipline of gender-specific medicine. Medical Clinics of North America 87 917-937.

Li M, Healy DR, Li Y, Simmons HA, Su M, Jee WS, Shen VW \& Thompson DD 2004 Alfacalcidol prevents age-related bone loss and causes an atypical pattern of bone formation in aged male rats. Journal of Musculoskeletal and Neuronal Interactions 4 22-32.

MacGillivray MH, Morishima A, Conte F, Grumbach M \& Smith EP 1998 Pediatric endocrinology update: an overview. The essential roles of estrogens in pubertal growth, epiphyseal fusion and bone turnover: lessons from mutations in the genes for aromatase and the estrogen receptor. Hormone Research 49 2-8. 
Majima T, Komatsu Y, Shimatsu A, Satoh N, Fukao A, Ninomiya K, Matsumura T \& Nakao K 2008 Efficacy of combined treatment with raloxifene and alfacalcidol on bone density and biochemical markers of bone turnover in postmenopausal osteoporosis. Endocrine Journal 55 127-134.

Maor G, Segev Y \& Phillip M 1999 Testosterone stimulates insulin-like growth factor-1 and insulin-like growth factor-1 receptor gene expression in the mandibular condyle - a model of endochondral ossification. Endocrinology 140 1901-1910.

Meinel L, Zoidis E, Zapf J, Hassa P, Hottiger MO, Auer JA, Schneider R, Gander B, Luginbuehl V, Bettschart-Wolfisberger R et al. 2003 Localized insulin-like growth factor I delivery to enhance new bone formation. Bone 33 660-672.

Melkko J, Kauppila S, Niemi S, Risteli L, Haukipuro K, Jukkola A \& Risteli J 1996 Immunoassay for intact aminoterminal propeptide of human type I procollagen. Clinical Chemistry 42 947-954.

Nilsson A, Isgaard J, Lindahl A, Dahlström A, Skottner A \& Isaksson OG 1986 Regulation by growth hormone of number of chondrocytes containing IGF-I in rat growth plate. Science 233 571-574.

Nilsson S, Mäkelä S, Treuter E, Tujague M, Thomsen J, Andersson G, Enmark E, Pettersson K, Warner M \& Gustafsson J 2001 Mechanisms of estrogen action. Physiological Reviews 81 1535-1565.

Nishikawa T, Ogawa S, Kogita K, Manabe N, Katsumata T, Nakamura K \& Kawaguchi H 2000 Additive effects of combined treatment with etidronate and alfacalcidol on bone mass and mechanical properties in ovariectomized rats. Bone 27 647-664.

Nuti R, Bianchi G, Brandi ML, Caudarella R, D’Erasmo E, Fiore C, Isaia GC, Luisetto G, Muratore M, Oriente P et al. 2006 Superiority of alfacalcidol compared to vitamin D plus calcium in lumbar bone mineral density in postmenopausal osteoporosis. Rheumatology International 26 445-453.

Parfitt AM, Drezner MK, Glorieux FH, Kanis JA, Maluche H, Meunier PJ, Ott SM \& Recker RR 1987 Bone histomorphometry: standardization of nomenclature, symbols, and units. Report of the ASBMR Histomorphometry Nomenclature Committee. Journal of Bone and Mineral Research 2 595-610.

Phillip M, Maor G, Assa S, Silbergeld A \& Segev Y 2001 Testosterone stimulates growth of tibial epiphyseal growth plate and insulin-like growth factor-1 receptor abundance in hypophysectomized and castrated rats. Endocrine 16 1-6.

Riggs BL, Khosla S \& Melton LJ III 2002 Sex steroids and the construction and conservation of the adult skeleton. Endocrine Reviews 23 279-302.

Ringe JD, Farahmand P, Schacht E \& Rozehnal A 2007 Superiority of a combined treatment of alendronate and alfacalcidol compared to the combination of alendronate and plain vitamin $\mathrm{D}$ or alfacaocidol alone in established postmenopausal or male osteoporosis. Rheumatology International 27 425-434.

Rissanen JP, Suominen MI, Peng Z, Morko J, Rasi S, Risteli J \& Halleen JM 2008 Short-term changes in serum P1NP predict long-term changes in trabecular bone in the rat ovariectomy model. Calcified Tissue International 82 155-161.
Schacht E, Richy F \& Reginster JY 2005 The therapeutic effects of alfacalcidol on bone strength, muscle metabolism and prevention of falls and fractures. Journal of Musculoskeletal \& Neuronal Interactions 5 273-284.

Shankar S \& Hosking DJ 2006 Biochemical assessment of Paget's disease of bone. Journal of Bone and Mineral Research 21 P22-P27.

Shen CL, Wang P, Guerrieri J, Yeh JK \& Wang JS 2008 Protective effect of green tea polyphenols on bone loss in middle-aged female rats. Osteoporosis International 19 979-990.

Shibata T, Shira-Ishi A, Sato T, Masaki T, Sasaki A, Masuda Y, Hishiya A, Ishikura N, Higashi S, Uchida Y et al. 2002 Vitamin D hormone inhibits osteoclastogenesis in vivo by decreasing the pool of osteoclast precursors in bone marrow. Journal of Bone and Mineral Research 17 622-629.

Shiraishi A, Higashi S, Ohkawa H, Kubodera N, Hirasawa T, Ezawa I, Ikeda K \& Ogata E 1999 The advantage of alfacalcidol over vitamin D in the treatment of osteoporosis. Calcified Tissue International 65 311-316.

Shiraishi A, Takeda S, Masaki T, Higuchi Y, Uchiyama Y, Kubodera N, Sato K, Ikeda K, Nakamura T, Matsumoto T et al. 2000 Alfacalcidol inhibits bone resorption and stimulates formation in an ovariectomized rat model of osteoporosis: distinct from estrogen. Journal of Bone and Mineral Research $15770-779$.

Shulman DI, Francis GL, Palmert MR \& Eugster EA 2008 Use of aromatase inhibitors in children and adolescents with disorders of growth and adolescent development. Pediatrics 121 e975-e983.

Soliman AT, Al Khalaf F, Alhemaidi N, Al Ali M, Al Zyoud M \& Yakoot K 2008 Linear growth in relation to the circulating concentrations of insulinlike growth factor I, parathyroid hormone, and 25-hydroxy vitamin D in children with nutritional rickets before and after treatment: endocrine adaptation to vitamin D deficiency. Metabolism 57 95-102.

Szabo A, Merke J, Beier E, Mall G \& Ritz E 1989 1,25 (OH $)_{2}$ Vitamin $D_{3}$ inhibits parathyroid cell proliferation in experimental uremia. Kidney International 35 1049-1056.

Thurlimann B, Keshaviah A, Coates AS, Mouridsen H, Mauriac L, Forbes JF et al. 2005 Breast International Group (BIG) 1-98 Collaborative Group. A comparison of Letrozole and tamoxifen in postmenopausal women with early breast cancer. New England Journal of Medicine 353 2747-2757.

Turnquist J, Ornoy A, Eini D \& Schwartz Z 1992 Effects of 1 alpha $(\mathrm{OH})$-vitamin $\mathrm{D}_{3}$ and $24,25(\mathrm{OH})_{2}$-vitamin $\mathrm{D}_{3}$ on long bones of glucocorticoid-treated rats. Acta Anatomica 145 61-67.

Vanderschueren D, Vandenput L, Boonen S, Linberg MK, Bouillon R \& Ohlsson C 2004 Androgens and bone. Endocrine Reviews 25 389-425.

Zung A, Phillip M, Chalew SA, Palese T, Kowarski AA \& Zadik Z 1999 Testosterone effect on growth and growth mediators of the GH-IGF-I axis in the liver and epiphyseal growth plate of juvenile rats. Journal of Molecular Endocrinology 23 209-221.

Received in final form 29 April 2009

Accepted 5 May 2009

Made available online as an Accepted Preprint 5 May 2009 